\title{
GSM Based Smart Energy Meter System
}

\author{
KANNAN P a,1, ALLWIN DEVARAJ a , ESAKKİ RAJAVEL. S a NISHARNI B ${ }^{\text {b }}$, \\ SANCTA $\mathrm{A}^{\mathrm{b}}$, MUTHU LAKSHMI $\mathrm{M}^{\mathrm{b}}$ \\ ${ }^{a}$ Assistant Professor, Francis Xavier Engineering College, \\ Tirunelveli, TN, India \\ ${ }^{b} U G$ Student, Francis Xavier Engineering College, Tirunelveli, TN, India
}

\begin{abstract}
This project aims to develop a smart energy meter which has many advantages like monitoring and controlling the energy meter at anywhere and at any place. Our project also called as pay first and then use it because here the user first has to pay the bill after that only they can consume the electricity. We know that each user has different kind of load demands and based on it we can recharge in number of units (KWh). The energy we are consuming and based on those pulses from the energy meter, microcontroller decrements the number of units and displays on LCD the remaining units we can use. The load gets disconnected when the units become zero and it is reconnected when the user recharges it. Our project will be very useful for the electricity board and also the user because this project gives the live update about the energy usage of the user through the message. GSM (Global system for mobile communication) will help to send and receive this information to the user. This system helps us to identify the energy losses of the electricity board to a large extent.
\end{abstract}

Keywords. Kilo Watt Hour, Liquid Crystal Display.

\section{Introduction}

In this modern world we are living in the "Automation world" because nowadays all are depending and addicted to this automation instead of the man power [1]. This kind of sustenance is now spreading in all nations particularly like our developing nations. Also, one of the most imminent thing in this world is Electricity which is highly used in many places such as for agricultural, industrial and also for household purposes. Although we enriched with electricity sources, till we are suffered with many problems in energy distribution, measuring the bill and controlling the energy consumption [2]. we know that electricity is playing an important role by giving coziness to our life so it should be used very carefully by without wasting it Electricity is one of the vital requirements for the sustainability of life's comforts and as such it must be used very wisely for its proper use [3]. But in our country, we have a lot of areas where we have surplus electricity supply while many areas cannot even get to it. Their distribution policies are also partly responsible for this because we still were unable to properly estimate us [4].

\footnotetext{
${ }^{1}$ KANNAN P, Assistant Professor, Francis Xavier Engineering College, Tirunelveli, TN, India; Email: kannamuthu1987@gmail.com.
} 
The implementation is done in such a way that SMS is delivered to GSM MODEM whose readability must be noted, and this metric is then returned to the server in SMS format and SMS costs are known to be very low [5]. GSM AMR takes advantage of available nationwide infrastructure coverage GSM and the cell broadcast feature of SMS system to order and retrieve individual homes and build reading power consumption back to the power supply wirelessly [6].

Goal of the proposed machine are

- To make energy intake prepaid.

- To centralize the manipulate of all energy meters.

- To prevent power thefts at consumer premises.

- To lessen fee of manpower for billing.

\section{Proposed System}

In the Figure 1, microcontroller, LCD and the GSM unit is interfaced with the power Meter of each house. every meter has a separate RR quantity, which is given with the aid of the electricity providing organizations [7]. the heart beat from the energy meter is given to optocoupler and output of the optocoupler is given to the microcontroller. The microcontroller constantly decrements the quantity of gadgets (1 unit $=1 \mathrm{kWh}$ ) as consistent with electricity consumption and shows the available gadgets on the LCD connected to the strength meter [8].

Output of power meter is attached to the weight via the relay. right here relay is used to attach or disconnect the supply to the burden. while the server (electricity supplying organisation) sends a request to the GSM modem, the modem commands the microcontroller to carry out the required action. The microcontroller in response sends the reply to the modem and the mod, in turn, sends the facts to the server. MAX232 is used for records switch between microcontroller and GSM modem [9].

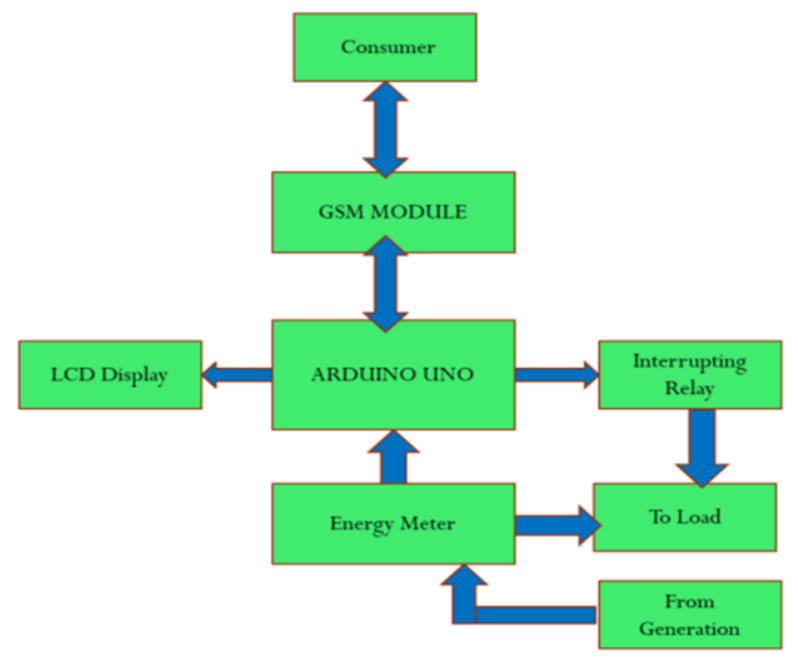

Figure 1. Block Diagram of GSM Module

GSM helps to deliver the Electricity fed on data to the application organization in addition when it is needed to the client. Aerial, connected close to meter container, which is mainly helped for development of signal energy in GSM. Automatic metering 
communique is the imminent thing in meter reading, so the maintenance staff from electricity board don't need to visit each consumer for meter reading [10]. Nevertheless, checking out and upkeep meters may additionally want to study from time to time. The primary responsibility of smart meter is to measure the energy that we have consumed and have to send it to software while call for also to consumer [1113]. The Effective values of voltage is measured by the voltage detector which is given to the micro controller, and inside the micro controller active and reactive energy calculations are carried out. In our project we have used current and voltage transformers and simultaneously as contradict to voltage detectors. A observation from the software organization is gained from the automatic energy meter which is a programmable one and the activities done by the meter is highly matched with the given enumeration a main advantage of automatic Energy meter is that we can disconnect and reconnect the power supply of the user without the help of the man power [14-15]. We can also reconnect the power supply once it is disconnected. The main characteristic of the Automatic Energy meter is that it alerts the client by ringing an alarm whilst the consumer load crosses the threshold restriction. If the consumer does not reduce his power usage then the meter automatically cut off the connection. GSM helps to deliver the energy ate up facts to the application management in addition to the consumer while demanded. Aerial, connected onor near meter container, maybe usedfor improvement of sign energy in GSM communication.

\section{Results and discussion}

We can also check the correctness of our proposed system by comparing the values which may be displayed in LCD display of Automatic energy meter and the units we have consumed also received through SMS. We can also check this system by connecting and disconnecting the client connections. Also we connected different loads to it and checked its overall performance. The checking out of SEM provided correct consequences, as a result verifying the performance and accuracy of the device. As shown in Figure 2, a basic connection is set up with a bread board with all additives like clever electricity Meter, lcd display, GSM Module, Load and so on.

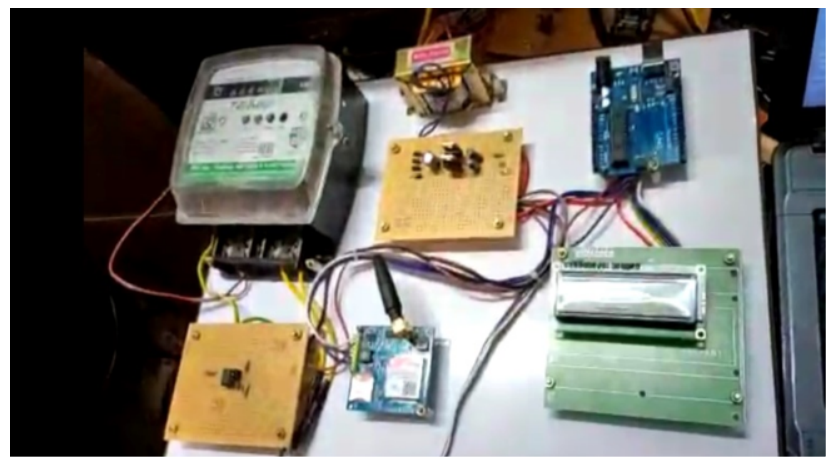

Figure 2. Overall setup with program dumped in GSM Module

Then program is dumped into the GSM Module in C language and then a kit is prepared and all soldering take place and the project is ready to execute. So once the program is dumped from the GSM Module a message alert saying System Ready reaches the person whose mobile number is registered. Once the system gets ready the 
load will automatically $\mathrm{ON}$ and the units and total balance is shown and it decreases as the power is consumed. The outputs are shown in Figures 3,4 and 5.

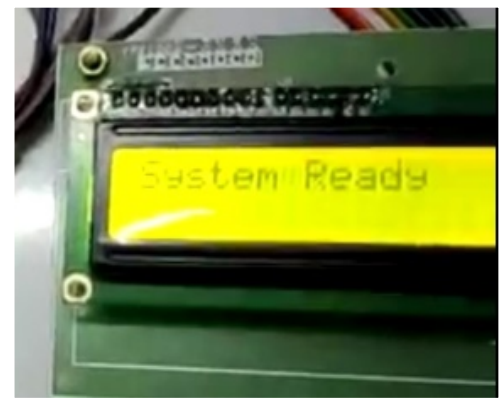

Figure 3. System Ready

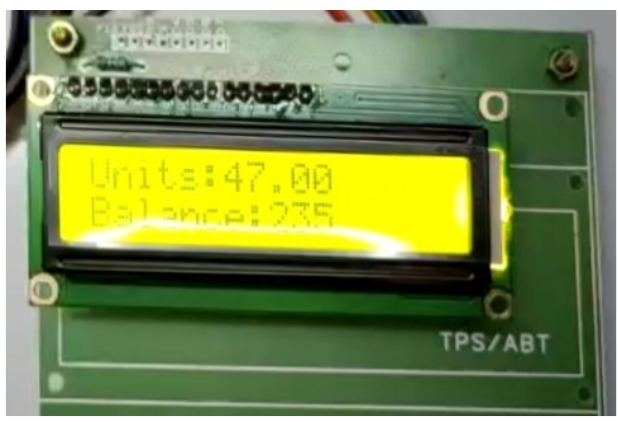

Figure 4. LCD Display of total units and balance

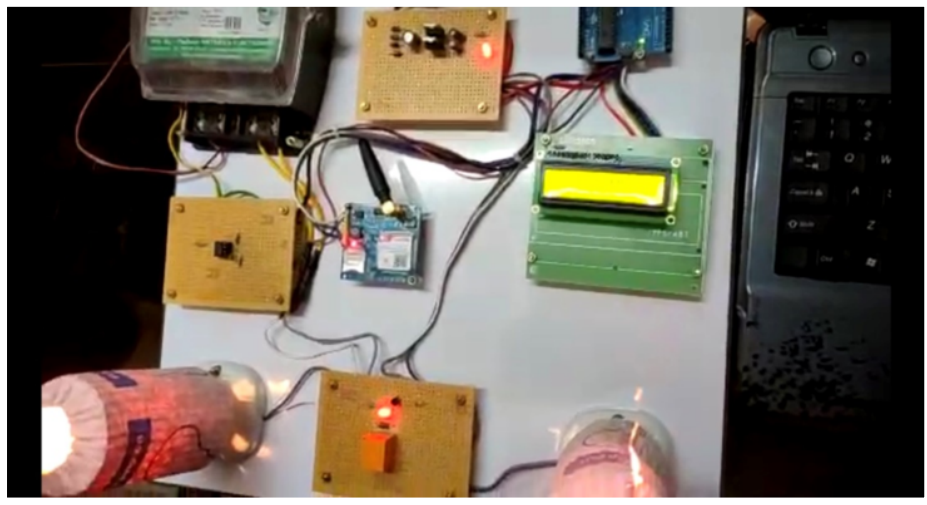

Figure 5. Final Output

\section{Conclusion}

The evolved GSM primarily based energy meter reading and billing are useful for each electricity provider supplying utility and customers. This machine overcomes the drawbacks of the conventional meter reading system and affords extra offerings together with energy cut and tampering alert. The evolved system additionally gives records about daily, month-to-month, and yearly electricity utilization details regarding day-by-day power intake will assist the customer to control their strength usage. This developed gadget is dependable and relaxed as best legal individuals can access the device.

\section{References}

[1] Amruta Chore, Prasad Mali, Dinesh Vyanjane, Vijay Karewar, 2018, "IOT Based Smart Electricity Meter and Billing System”, IRJET journal, vol: 05, no: 10, pp: 916-919.

[2] Yogesh B.Mandake, Abhishek Pandey, Mohit Sareen, Pratyush Prasoon, Rishav Raj, Ayush Agrawal, 2020, “GSM Based Smart Energy Meter”, IRJET journal, vol:07, no: 06, pp: 7618- 7621.

[3] Tejas Chate, Aniket Kahalkar, Prashant Soni, Dinesh Gawande, 2017, "A Review on GSM Based Monthly Electrical Energy Billing through SMS”, IRJET journal, vol: 04, no: 03, pp: 1068-1069. 
[4] Shital S. Bobade, Vibhuti S. Jadhav, Anuja A. Mokal, K. D. Mahajan, 2016, "Automatic Energy Meter Billing System with Theft Detection”, IRJET journal, vol: 03, no: 04, pp: 237-240.

[5] Swapnil V. Vanmore, Prathamesh Avalekar, Indrajeet Patil, 2016, "Prepaid and Postpaid Energy Meter for Billing System Using Microcontroller and GSM”, IRJET journal, vol: 03, no: 02, pp: 12141216.

[6] K. Sindhuja, M. Sravya, Y. Rajkumar, P. Anjali rao, J. Ravichander, 2020, "Electricity Energy Meter using IoT", IRJET journal, vol: 07, no: 04, pp: 1177-1182.

[7] Vairaperumal K, Dinesh M, Senthilkumar P, Mubeena S, 2018, "Effective Energy Measurement and Billing System Using Arduino GSM Shield”, IRJET journal, vol: 05, no: 11, pp: 836-840.

[8] Darshit S. Patel, H.B. Patel, 2017, "GSM Based Energy Meter Monitoring and Load Control" IRJET journal, vol: 04, no: 03, pp: 360-363.

[9] Seema More, Arati Kumbhar, Jyoti Chavan, Prof. Ghewari M.U, 2019, "Smart Energy Meter Billing, Monitoring and Controlling System", IRJET journal, vol: 06, no: 03, pp: 3420-3424.

[10] Kiran Mohite, Nisha Kadam, Aishwarya Kadam, Ramchandra Gurav, 2019, "Smart Prepaid Energy Meter Using GSM Technology”, IRJET journal, vol: 06, no: 03, pp: 5079-5082.

[11] Shivam Roy, Shreyans Patel, Mahir Udepurwala, 2019, "IOT Based Prepaid Energy Meter", IRJET journal, vol: 06, no: 03, pp: 1158-1161.

[12] Tejas Gujrati, E Terence, 2019, "ESP8266 Based Pre-Paid Electricity System”, IRJET journal, vol: 07, no: 06, pp: 682-685.

[13] Pooja S. Vaidya, Chanchal S. Kature, Sonali G. Waghmare, Ms. S. A. Dhumane, 2019, "IOT Based Energy Meter Billing System", IJASRET journal, vol: 04, no: 05, pp: 4-6.

[14] A.Subba Rao, Sri VidyaGarige, 2019, "IOT Based Smart Energy Meter Billing Monitoring and Controlling the Loads", IJITEE journal, vol: 08, no: 4S2, pp: 340-344.

[15] Hannoon, N., Vijayakumar, V., Vengatesan, K., \& Hidayat, N. (2019). Small Signal Fault Analysis for Renewable Energy (Wind) Power System Distributed Generation by Using MATLAB Software (Simulink). Journal of Computational and Theoretical Nanoscience, 16(2), 537-543.

[16] Shivprasad S. More, Ketaki K. Korane, Akshaykumar K. Khamkar, Aditya V. Jadhav, Nachiket C. Keripale, Ajay B. Shinde, 2020, "Prepaid Energy Meter System”, IRJET journal, vol: 07, no: 06, pp: 4771-4775. 